\title{
How to Have Difficult Conversations with your Patients
}

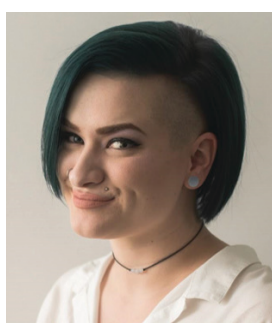

\section{Kaia Pankhurst}

As Marketing4ECPs' Senior Content Strategist, Kaia Pankhurst creates and implements content strategies for eye care practices all over North America. Outside of the office, Kaia is a musician, activist, and professional wrestler. You can reach Kaia at marketing4ecps.com

$\mathrm{J}$ ust like any medical professional, Optometrists occasionally have to broach difficult topics with their patients. Whether it's a frightening diagnosis, an expired frame warranty, or even just some unfortunate news about insurance coverage, these conversations are an unavoidable part of the job.

Neither patient nor practitioner looks forward to these sorts of discussions, but sweeping them under the rug is never an option. The best thing to do is to approach tough subjects with compassion, grace, and clarity.

Here are a few strategies you can use when having difficult conversations with your patients.

\section{MAP THE CONVERSATION}

Prepare for the discussion before initiating it. Start by determining your essential message. What do you need to communicate? Cover the necessary information, ideally in a few short sentences, then open up a dialogue.

One method you could consider is the ask-answer-ask strategy, where you ask the patient for their primary concern, answer their question, then follow up by asking if they feel you have satisfied the question.

For a more comprehensive plan, try using the SPIKES strategy:

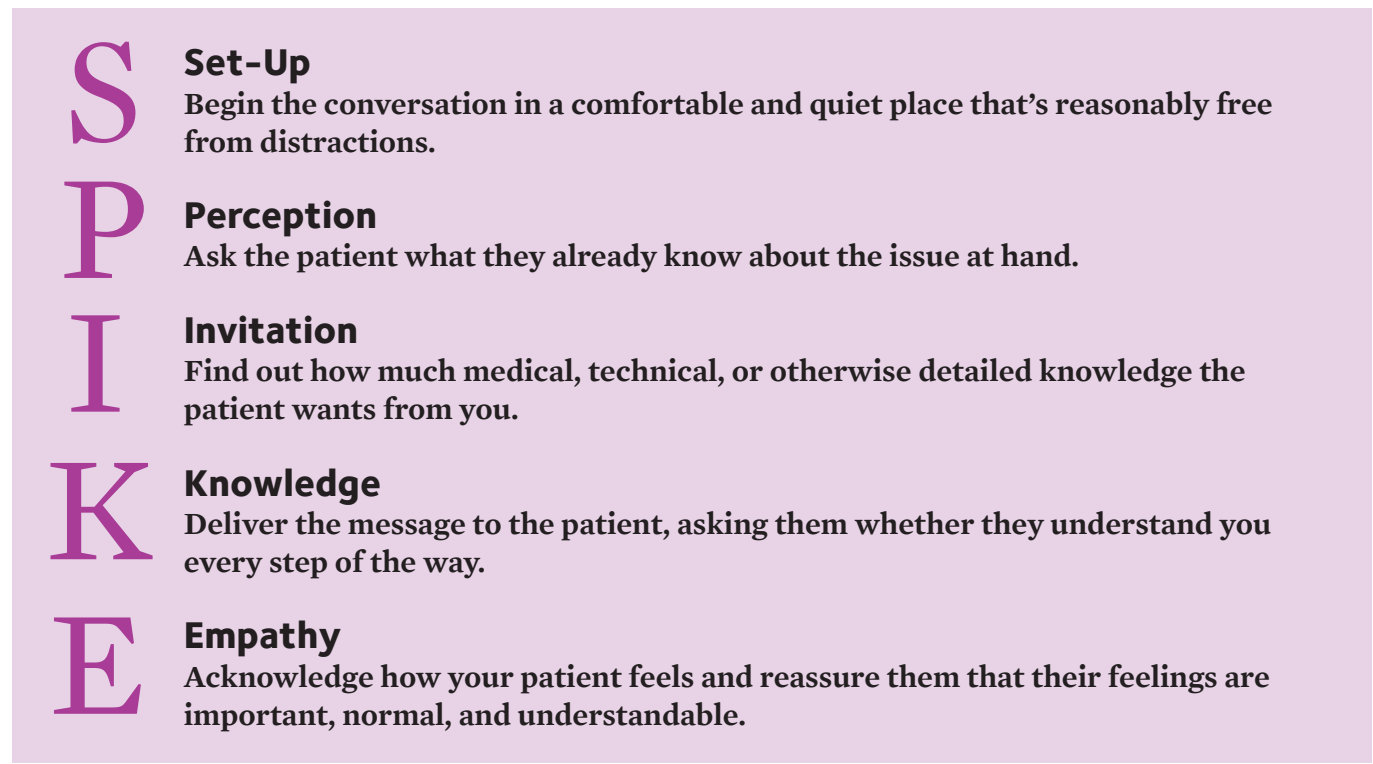

Ask your patient if they have any questions. Once you've answered each one, confirm that your answer satisfied their question. Once the patient feels ready, you can tell them what the next steps in their treatment will be. 
GIVE THEM SOMEWHERE TO GO

Obviously, you can't offer complete emotional support to all of your patients. But you may help them find a support system outside of your office. Do a little bit of research and build up a database of support groups, mentors, charitable organizations, and other places that provide help and support for people like your patient.

By showing your patient that they're not alone, you can help them transition to their new reality. Doing so shows that you care about their overall health and wellbeing.

\section{STAY PRESENT}

Empathy and emotional vulnerability can be uncomfortable. Many medical professionals tend to shut off their more "human" impulses during difficult conversations, using medical or technical jargon instead of engaging in a dialogue.

While this can be a natural response, it can further confuse, frighten, or frustrate patients.

It's important to stay emotionally present during these scenarios. Offer information in layman's terms. Explain medical language, and try to offer analogies where appropriate to add context. Do whatever you can to engage with your patient rather than present information to your patient. Be open to saying “I'm sorry”, when it's applicable.

REMEMBER YOU ARE HUMAN TOO

Difficult conversations take a toll on everyone involved. If you are going to communicate difficult news to a patient, you also need emotional support. Whether it is friends, family, or colleagues, ensure you have a network of people to offer you help and strength on difficult days.

Take time to process whatever feelings you may have. Participate in activities that restore your energy and put you in a position to give your patients the best possible experience. 